\title{
A theoretical insight into the catalytic effect of a mixed-metal oxide at the nanometer level: The case of the highly active metal $/ \mathrm{CeO}_{x} / \mathrm{TiO}_{2}(110)$ catalysts
}

Cite as: J. Chem. Phys. 132, 104703 (2010); https://doi.org/10.1063/1.3337918

Submitted: 17 December 2009 . Accepted: 05 February 2010 . Published Online: 09 March 2010

Jesús Graciani, José J. Plata, Javier Fdez. Sanz, Ping Liu, and José A. Rodriguez

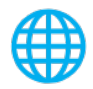

\section{ARTICLES YOU MAY BE INTERESTED IN}

A climbing image nudged elastic band method for finding saddle points and minimum energy paths

The Journal of Chemical Physics 113, 9901 (2000); https://doi.org/10.1063/1.1329672

A consistent and accurate ab initio parametrization of density functional dispersion correction (DFT-D) for the 94 elements H-Pu

The Journal of Chemical Physics 132, 154104 (2010); https://doi.org/10.1063/1.3382344

Improved tangent estimate in the nudged elastic band method for finding minimum energy paths and saddle points

The Journal of Chemical Physics 113, 9978 (2000); https://doi.org/10.1063/1.1323224

\section{Lock-in Amplifiers up to $600 \mathrm{MHz}$}
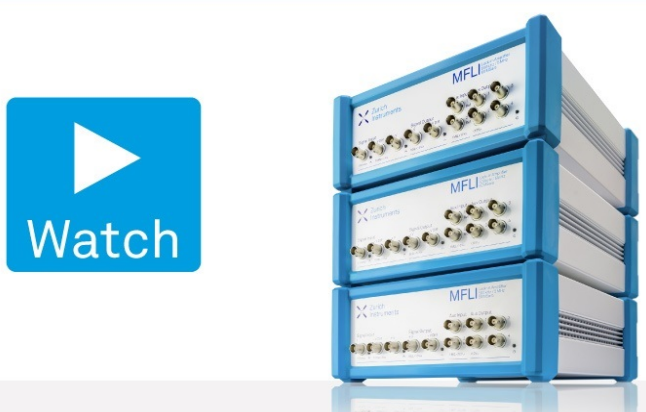


\title{
A theoretical insight into the catalytic effect of a mixed-metal oxide at the nanometer level: The case of the highly active metal/ $\mathrm{CeO}_{x} / \mathrm{TiO}_{2}(110)$ catalysts
}

\author{
Jesús Graciani, ${ }^{1,2, a)}$ José J. Plata, ${ }^{2}$ Javier Fdez. Sanz, ${ }^{2}$ Ping Liu, ${ }^{1}$ and José A. Rodriguez ${ }^{1}$ \\ ${ }^{1}$ Department of Chemistry, Brookhaven National Laboratory, Upton, New York 11973, USA \\ ${ }^{2}$ Departamento de Química Física, Facultad de Química, Universidad de Sevilla, Sevilla E-41012, Spain
}

(Received 17 December 2009; accepted 5 February 2010; published online 9 March 2010)

\begin{abstract}
The structural and electronic properties of $\mathrm{CeO}_{x}$ species supported on the rutile $\mathrm{TiO}_{2}(110)$ surface have been examined by means of periodic density-functional calculations that use a generalized gradient approximation functional including a Hubbard-like type correction. Deposition of Ce atoms leads in a first step to $\mathrm{Ce}^{3+}$ ions bound to the surface through bridge and in-plane oxygen atoms, the released electrons occupying the Ti $3 d$ empty orbitals. Further addition of $\mathrm{Ce}$ and molecular oxygen gives place to $\mathrm{Ce}_{2} \mathrm{O}_{3}$ dimers diagonally arranged on the surface, in agreement with the spots observed in the scanning tunnel microscope images. The formation process of $\mathrm{CeO}_{x}$ nanoparticles (NPs) on the $\mathrm{TiO}_{2}$ surface is highly exothermic and our calculations show that the redox properties of the $\mathrm{Ce}(\mathrm{III})-\mathrm{Ce}(\mathrm{IV})$ couple are significantly altered when it is supported on $\mathrm{TiO}_{2}$. In particular the reactivity against $\mathrm{CO} / \mathrm{O}_{2}$ indicates that on the surface the presence of $\mathrm{Ce}$ (III) is favored over $\mathrm{Ce}$ (IV) species. Our results also indicate that the $\mathrm{CeO}_{x} / \mathrm{TiO}_{2}$ interface should be seen like a real mixed-metal oxide rather than a supported NP of ceria. Finally, in the context of the high catalytic activity of the $M / \mathrm{CeO}_{x} / \mathrm{TiO}_{2}(M=\mathrm{Au}, \mathrm{Cu}, \mathrm{Pt})$ systems in the water-gas shift reaction, we have examined the dissociation of water on the $\mathrm{CeO}_{x} / \mathrm{TiO}_{2}$ surface and estimated a barrier as small as $0.04 \mathrm{eV}$, i.e. $\sim 8$ times smaller than that computed for a $\mathrm{TiO}_{2}$ oxygen vacancy. This result agrees with the experimental superior catalytic activity of the $M / \mathrm{CeO}_{x} / \mathrm{TiO}_{2}$ systems over $M / \mathrm{TiO}_{2}$. (C) 2010 American Institute of Physics. [doi:10.1063/1.3337918]
\end{abstract}

\section{INTRODUCTION}

Catalytic processes able to reduce the environmental pollution or generate new clean renewable sources of energy have received an increasing attention and become one of the hot spots in chemistry. ${ }^{1-5}$ In this regard, a number of works have been devoted to design new better catalyst intended to eliminate $\mathrm{CO}$, either by plane oxidation $\left(\mathrm{CO}+\frac{1}{2} \mathrm{O}_{2} \rightarrow \mathrm{CO}_{2}\right)$ or further transformation through, for instance, the water gas shift (WGS) reaction, $\left(\mathrm{CO}+\mathrm{H}_{2} \mathrm{O} \rightarrow \mathrm{CO}_{2}+\mathrm{H}_{2}\right)$, widely used to produce $\mathrm{H}_{2}$ clean enough to be used in fuel cells. ${ }^{3-7}$ Many metal/metal-oxide systems have been found to catalyze these important reactions under different conditions, and among them, two of the most efficient systems are based on gold nanoparticles (NPs), supported on a reducible metal oxide such as titania or ceria $\left(\mathrm{Au} / \mathrm{TiO}_{2}\right.$ and $\left.\mathrm{Au} / \mathrm{CeO}_{2}\right){ }^{3-15}$ The ability of both systems to easily generate reduced species of $\mathrm{Ti}$ and $\mathrm{Ce}\left(\mathrm{Ti}^{3+} / \mathrm{Ce}^{3+}\right)$ has been found to play a crucial role on their catalytic activities. ${ }^{16-19}$

In the WGS reaction, previous work performed on a variety of systems such as $\mathrm{Au} / \mathrm{CeO}_{2}, \mathrm{Au} / \mathrm{TiO}_{2}, \mathrm{Au} / \mathrm{TiO}_{2-x} \mathrm{~N}_{y}$, $\mathrm{Cu} / \mathrm{TiO}_{2}, \quad \mathrm{CeO}_{x} / \mathrm{Au}(111), \quad \mathrm{CeO}_{x} / \mathrm{Cu}(111), \quad$ and $\mathrm{Au} / \mathrm{CeO}_{x} / \mathrm{TiO}_{2}$, has shown that the main role of the metal is to adsorb $\mathrm{CO}$ while the role of the oxide is to dissociate water. $^{12,20-23}$ Although all the steps involved in the WGS

\footnotetext{
${ }^{a)}$ Author to whom correspondence should be addressed. Electronic mail: graciani@us.es.
}

reaction might occur on the surface of the metal, or metal $\mathrm{NP}$, the high activation barriers estimated for the dissociation of $\mathrm{H}_{2} \mathrm{O}$ makes the bare metal a quite inefficient catalyst. ${ }^{24,25}$ That is why it is critical that the properties of the oxide facilitate $\mathrm{H}_{2} \mathrm{O}$ dissociation. ${ }^{20,12} \mathrm{On}$ its turn, metal-oxide surfaces readily adsorb water, and are able to dissociate $\mathrm{H}_{2} \mathrm{O}$ easily, mainly at the $\mathrm{O}$ vacancy sites, to produce hydroxyls that cover the surface. However, in a WGS environment, these hydroxyls usually react with $\mathrm{CO}$ to give rise to very stable intermediates $\left(\mathrm{HCOO}, \mathrm{CO}_{x}\right)$ that stop the reaction. ${ }^{20}$ Therefore, an adequate combination of the metal oxide and metal properties leads to a high active catalyst: $\mathrm{H}_{2} \mathrm{O}$ is easily dissociated on the oxide and less stable intermediates which evolve to products with low activation barriers are formed on the metal particle or at the interface.

Oxygen vacancies, which involve the presence of $\mathrm{Ti}^{3+}$ or $\mathrm{Ce}^{3+}$ species, are the main active sites for dissociative chemisorption of water on $\mathrm{TiO}_{2}$ and $\mathrm{CeO}_{2} \cdot{ }^{20,12,22,26-31}$ Therefore the presence of reduced species $\mathrm{Ti}^{3+}$ or $\mathrm{Ce}^{3+}$ is essential to achieve high catalytic activity in the WGS. For instance, a catalyst consisting of $\mathrm{CeO}_{x}$ NPs supported on $\mathrm{Au}(111)$ has activities higher than those of standard WGS catalysts such as $\mathrm{Cu}(111)$ or $\mathrm{Cu}(100){ }^{20}$ The activity was found to be directly related to the presence of some $\mathrm{Ce}^{3+}$ species. Another way to enlarge the concentration of active $\mathrm{Ce}^{3+}$ sites is to modify the pure oxide by mixing it with a different metal oxide. The properties of these mixed-metal oxides can be very different from those of the pure oxides. Higher effects 
can be expected by mixing the oxides at the nanometer level. In fact, in our previous work ${ }^{21}$ we have shown that the growing of $\mathrm{CeO}_{x}$ NPs on $\mathrm{TiO}_{2}$ leads to the formation of some structures of cerium oxide imposed by the interaction with the host oxide in which the relative stability of $\mathrm{Ce}^{4+} / \mathrm{Ce}^{3+}$ is strongly affected to the point that all $\mathrm{Ce}$ atoms are in $\mathrm{a}+3$ oxidation state. Deposition of $\mathrm{Au}$ nanoclusters on these mixed metal-oxide $\mathrm{CeO}_{x} / \mathrm{TiO}_{2}$ surfaces leads to catalysts that show a dramatic improvement in the activity, even larger than that observed for the WGS on $\mathrm{CeO}_{x} / \mathrm{Au}(111)$ or $\mathrm{Au} / \mathrm{CeO}_{2} \cdot{ }^{20,21}$ Extremely high WGS activity is also found for the $\mathrm{Cu} / \mathrm{CeO}_{x} / \mathrm{TiO}_{2}(110)$ and $\mathrm{Pt} / \mathrm{CeO}_{x} / \mathrm{TiO}_{2}(110)$ systems. $^{32}$

Although a direct influence of the mixed-metal oxide properties on the catalytic activity has been suggested, a detailed analysis of the $\mathrm{CeO}_{x} / \mathrm{TiO}_{2}$ interface at the electronic level has not yet been reported. For instance, the origin of the predominance of $\mathrm{Ce}^{3+}$ over $\mathrm{Ce}^{4+}$ species at the surface, or the ability of such a system to dissociate water molecules, still remain open questions. In the present paper we report a theoretical work based on periodic density-functional calculations of the formation process of $\mathrm{CeO}_{x} \mathrm{NPs}$ on the $\mathrm{TiO}_{2}$ surface from the interaction of $\mathrm{Ce} / \mathrm{TiO}_{2}$ with $\mathrm{O}_{2}$, as well as their redox properties, e.g., their reactions with $\mathrm{CO} / \mathrm{O}_{2}$. We study the relation between the geometrical and electronic structures and their impact on the reactivity. Finally we examine the interaction and dissociation of water on the $\mathrm{CeO}_{x} / \mathrm{TiO}_{2}$ surface. Since the $\mathrm{TiO}_{2-x}$ system has also been found to be a good system for the dissociative chemisorption of water, and the formation of $\mathrm{TiO}_{x}$ species on the surface of $\mathrm{TiO}_{2}$ from interstitial Ti has been recently shown, ${ }^{33}$ we have also performed some calculations for the $\mathrm{TiO}_{x} / \mathrm{TiO}_{2}$ system in order to compare it with $\mathrm{CeO}_{x} / \mathrm{TiO}_{2}$.

\section{DENSITY-FUNCTIONAL CALCULATIONS}

The density functional theory (DFT) calculations were performed using the plane-wave-pseudopotential approach within the projector augmented wave method ${ }^{34}$ together with the GGA exchange correlation functional proposed by Perdew et $a l .{ }^{35}$ as implemented in the VASP 4.6 code. $^{36,37} \mathrm{~A}$ plane-wave cutoff energy of $400 \mathrm{eV}$ was used. We treated the $\mathrm{Ti}(3 s, 3 p, 3 d, 4 s), \mathrm{Ce}(4 f, 5 s, 5 p, 5 d, 6 s)$, and $\mathrm{O}(2 s, 2 p)$ electrons as valence states, while the remaining electrons were kept frozen as core states. To obtain faster convergence, thermal smearing of one-electron states $\left(k_{B} T=0.05 \mathrm{eV}\right)$ was allowed using the Gaussian smearing method to define the partial occupancies. We chose a $(4 \times 2)$ surface model with the aim to have isolated $\mathrm{CeO}_{x}$ monomers and dimers on the $\mathrm{TiO}_{2}(110)$ surface. The distance between two nearest $\mathrm{Ce}_{2} \mathrm{O}_{3}$ dimers was $\sim 6 \AA$, which is a reasonable distance with a computationally affordable model. In order to avoid spurious effects due to the finite thickness of the slab representing the surface, we used a recently published model of six layers. ${ }^{38,39}$ In this model the two lowest layers were fixed at the optimized atomic bulk positions while atoms in the upper four layers were allowed to relax. This surface model has been shown to minimize the well-known energy oscillations as a function of the number of layers (even-odd) and reaches convergence for both the geometric and electronic surface structures. $^{38,39}$ This surface model, that amounts to 288 atoms, has been successfully used in previous works. ${ }^{21,22,40,41}$ The energy was estimated at the gamma point. In order to represent adequately the electronic structure of $\mathrm{Ce}$ (in particular the $4 f$ level of the $\mathrm{Ce}^{3+}$ species) we used the GGA $+U$ formalism. The Hubbard $U$ term was added to the plain GGA functional employing the rotationally invariant approach proposed by Dudarev et al., ${ }^{42}$ in which the Coulomb $U$ and exchange $J$ parameters are combined into a single parameter $U_{\text {eff }}=U-J$. For Ce we have used the $U_{\text {eff }}$ of 4.5 $\mathrm{eV}$ which was self-consistently calculated by Fabris et al. ${ }^{43}$ using the linear-response approach of Cococcioni and de Gironcoli $^{44}$ and which is in the range of values usually proposed in the literature $(4.5-5.5 \mathrm{eV})$ for $\mathrm{GGA}+U$ calculations. ${ }^{45-53}$ For the $3 d$ states of Ti we also chose a $U_{\text {eff }}$ parameter of $4.5 \mathrm{eV}$ as it reproduces the experimental values of the gap between the $\mathrm{Ce}^{3+} 4 f$ and $\mathrm{Ti}^{3+} 3 d$ levels observed in the valence photoemission spectra of $\mathrm{Ce} / \mathrm{TiO}_{2}(110)$ system. ${ }^{21}$ Although lower values for $U_{\text {eff }}$ have also been proposed for a balanced description of bulk $\mathrm{CeO}_{2}$ and $\mathrm{Ce}_{2} \mathrm{O}_{3}$ oxides, ${ }^{54,55}$ the set of parameters we have selected allows for a correct description of the gaps observed in the experimental photoemission spectra of our systems consisting of $\mathrm{CeO}_{x}$ clusters supported on the $\mathrm{TiO}_{2}(110)$ surface. ${ }^{21}$ Furthermore, the presence of $\mathrm{Ce}^{3+}$ species was indicated by a characteristic $4 f$ peak in the band gap and later confirmed by the magnetization of the $\mathrm{Ce}$ atoms (higher than 0.9 electrons) found in the calculations.

The adsorption energy for a given species $X$ (where $X$ stands for $\mathrm{Ce}$ atom, $\mathrm{H}_{2} \mathrm{O}, \mathrm{CO}$, etc.) has been calculated as

$$
E_{\mathrm{ads}}(X)=E\left(X / \mathrm{TiO}_{2}\right)-E(X)-E\left(\mathrm{TiO}_{2}\right),
$$

where $E_{\mathrm{ads}}(X)$ is the adsorption energy of $X$ on $\mathrm{TiO}_{2}(110)$, $E\left(X / \mathrm{TiO}_{2}\right)$ is the total energy of the system in which $X$ is adsorbed on the $\mathrm{TiO}_{2}(110)$ surface, $E(X)$ is the energy of the isolated $X$ and $E\left(\mathrm{TiO}_{2}\right)$ is the energy of the slab model of the surface.

Transitions states have been calculated by using the climbing image (CI) version of the nudged elastic band (NEB) algorithm ${ }^{56}$ and in all cases, after a vibrational analysis, a single imaginary frequency has been obtained for these structures. Since these calculations have a huge computational cost in the transitions state searches, the model was reduced to four layers. The reliability of this reduced model was verified by comparing the reaction energy for the water dissociation at the surface from both models: $-0.70 \mathrm{eV}$ (sixlayer thick model) versus $-0.64 \mathrm{eV}$ (four-layer thick model).

\section{RESULTS AND DISCUSSION}

\section{A. Growth of the $\mathrm{CeO}_{x}$ particles on $\mathrm{TiO}_{2}(110)$}

Previous scanning tunneling microscopy (STM) results have shown the formation of $\mathrm{CeO}_{x}$ NPs when depositing $\mathrm{Ce}$ on $\mathrm{TiO}_{2}(110)$ in oxygen atmosphere. ${ }^{21}$ At low Ce coverage, two kinds of $\mathrm{CeO}_{x}$ spots were identified and assigned to single $\mathrm{Ce}$ atoms and $\mathrm{Ce}-\mathrm{Ce}$ dimers, which were bonded to bridge $\mathrm{O}$ atoms. To determine the structure, stability and oxidation state of these species, we have simulated a process of 


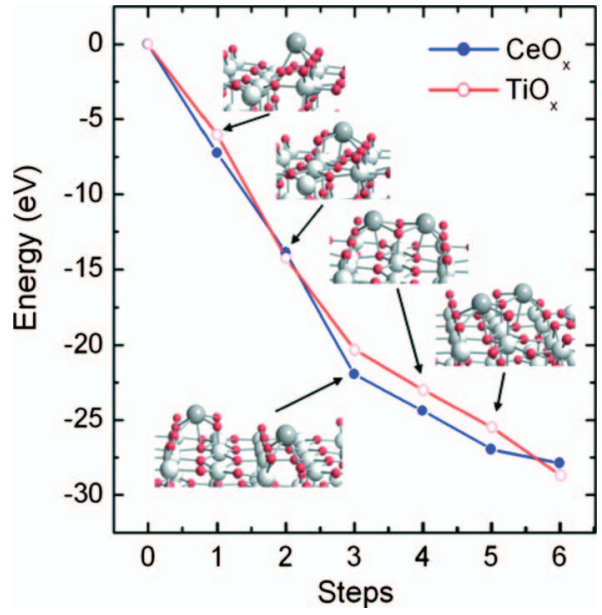

FIG. 1. Energy pathway for the formation of $\mathrm{CeO}_{x}$ and $\mathrm{TiO}_{x}$ species on $\mathrm{TiO}_{2}(110)$ starting from the adsorption of $\mathrm{Ce} / \mathrm{Ti}$ atoms and subsequent progressive interaction with $\mathrm{O}_{2} . M$ indicates $\mathrm{Ce}$ or Ti metal adatoms in each case. Colors: $\mathrm{Ce} / \mathrm{Ti}$ adatoms (dark gray), $\mathrm{Ti}$ atoms of the $\mathrm{TiO}_{2}$ support (soft gray) and $\mathrm{O}$ (soft red). Steps: (1) $M$ atom adsorption, (2) $\mathrm{O}_{2}$ adsorptiondissociation: formation of the 1st monomer $\left(M \mathrm{O}_{2}\right)$, (3) 2nd $M$ atom adsorption, (4) 1st dimer formation $\left(M_{2} \mathrm{O}_{2}\right),(5)(1 / 2) \mathrm{O}_{2}$ adsorption and 2nd dimer formation $\left(M_{2} \mathrm{O}_{3}\right)$, and $(6)(1 / 2) \mathrm{O}_{2}$ adsorption and degradation in monomers $\left(2 \mathrm{MO}_{2}\right)$.

sequential adsorption-oxidation for $\mathrm{Ce}$ deposited on $\mathrm{TiO}_{2}$. Figure 1 shows the energy pathway for such a process. The adsorption energy of the first $\mathrm{Ce}$ atom is very high $(-7.01$ $\mathrm{eV})$. On the most stable adsorption site the Ce atom is threefold coordinated and interacts with one $\mathrm{O}$ from the plane and two bridge $\mathrm{O}$ (see Fig. 1, step 1). The formal oxidation state is +3 , which gives rise to the characteristic $4 f$ peak above the O $2 p$ band on the projected density of states (DOS) (bottom panel in Fig. 2). Upon adsorption, the Ce atom $\left(6 s^{2} 5 d 4 f\right)$ formally releases three electrons to the oxide, that are transferred from the Ce $6 s$ and $5 d$ levels to the lower energy Ti $3 d$ states, reducing three $\mathrm{Ti}$ atoms to $\mathrm{Ti}^{3+}$. Two of them are

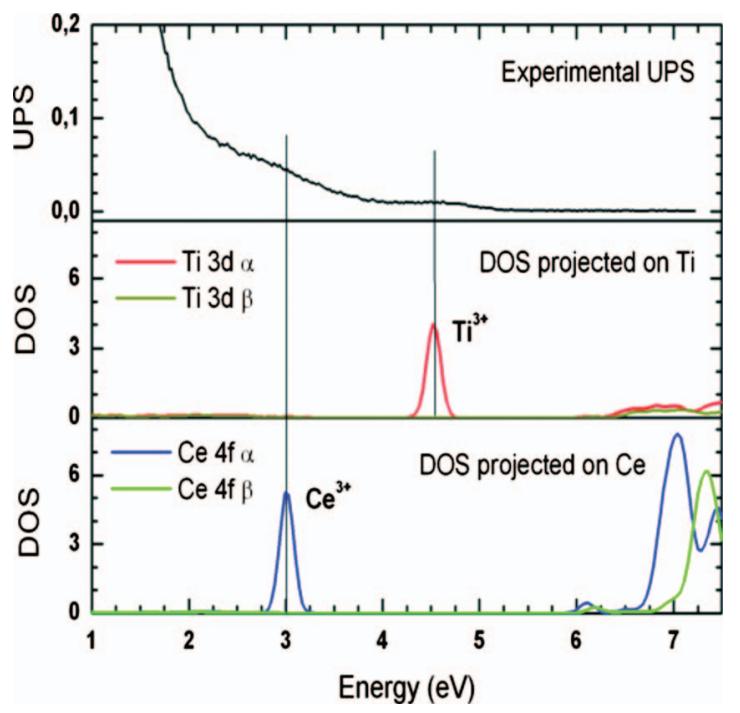

FIG. 2. Experimental photoemission spectrum (top) (Ref. 21), and calculated DOS projected on the reduced Ti atom (middle) and the adsorbed $\mathrm{Ce}$ atom (bottom) for the deposition of $\mathrm{Ce}$ on $\mathrm{TiO}_{2}(110)$. In the calculation the $U_{\text {eff }}$ parameter used for both Ce $4 f$ and Ti $3 d$ is $4.5 \mathrm{eV}$. (Reproduced from our previous work in Proc. Natl. Acad. Sci. U.S.A., Ref. 21). located in the surface layer and the third one is located in the subsurface layer. The fourth valence electron of Ce remains in a $4 f$ orbital, whose energy is lower than the empty Ti $3 d$ levels (Fig. 2), and therefore is not transferred, leaving the oxidation state of $\mathrm{Ce}$ as +3 . To make a $\mathrm{Ce}^{4+}$ ion it would be necessary to have empty states in the $\mathrm{O} 2 p$ band that is lower in energy than the Ce $4 f$ level. The high chemisorption energy that we calculated can be understood bearing in mind that there are two complementing contributions to the bond: the large stabilization of the three electrons that shift from high to low energy levels, $\operatorname{Ce}\left(5 d 6 s^{2}\right) \rightarrow \operatorname{Ti}(3 d)$, and the strong electrostatic energy gain that arises from the interaction of the $\mathrm{Ce}^{3+}$ cation with three surface $\mathrm{O}^{2-}$ anions. Thus, the adsorption process of atomic $\mathrm{Ce}$ involves direct bonding with $\mathrm{O}$ atoms of the titania and an electron transfer that could be described as

$$
\mathrm{Ce}+3 \mathrm{Ti}^{4+}\left(\mathrm{TiO}_{2}\right) \rightarrow \mathrm{Ce}^{3+}+3 \mathrm{Ti}^{3+}\left(\mathrm{TiO}_{2}\right) .
$$

On the other hand, to get $\mathrm{Ce}^{4+}$ ions on the stoichiometric oxide would need the presence of extra oxygen. Given that $\mathrm{CeO}_{x}$ species are formed in the presence of $\mathrm{O}_{2},{ }^{21}$ it is appropriate to study the interaction of adsorbed $\mathrm{Ce}$ with oxygen. The adsorption-dissociation of $\mathrm{O}_{2}$ over adsorbed atomic $\mathrm{Ce}$ is a highly exothermic process $(-6.88 \mathrm{eV})$. The final structure is a unit of $\mathrm{CeO}_{2}$ over $\mathrm{TiO}_{2}$, where the $\mathrm{O}$ atoms are adsorbed on the in-plane $\mathrm{Ti}$ atoms and strongly interact with the $\mathrm{Ce}$ atom that remains in the initial position (see Fig. 1, step 2). This structure is similar to that observed by Wendt $e t$ $a l .{ }^{33}$ for interstitial $\mathrm{Ti}$ interacting with $\mathrm{O}_{2}$ on the $\mathrm{TiO}_{2}(110)$ surface. The formal oxidation state of the $\mathrm{Ce}$ in this configuration is +4 . This was neatly observed on the projected DOS on $\mathrm{Ce}$ (not shown) where the characteristic $4 f$ peak of $\mathrm{Ce}^{3+}$ completely disappeared. A further electron rearrangement comes from the fact that to fill the $\mathrm{O} 2 p$ orbitals, in addition to the $\mathrm{Ce} 4 f$, three more electrons are needed, and therefore $3 \mathrm{Ti}^{3+}$, previously reduced, are reoxidized to $\mathrm{Ti}^{4+}$. This new multielectron transfer, together with the strong electrostatic $\mathrm{Ce}^{4+}-\mathrm{O}^{2-}$ interaction explain the high energy released in the process, which could be described as

$$
\mathrm{Ce}^{3+}+3 \mathrm{Ti}^{3+}\left(\mathrm{TiO}_{2}\right)+\mathrm{O}_{2} \rightarrow \mathrm{CeO}_{2}\left(\mathrm{Ce}^{4+}\right) \text { on } \mathrm{TiO}_{2} .
$$

We will call this $\mathrm{CeO}_{2}$ particle a monomer, which is identified as the small spots observed in STM images for $\mathrm{CeO}_{x} / \mathrm{TiO}_{2}(110){ }^{21}$

Deposition of the second $\mathrm{Ce}$ atom at a surface position far from the monomer (see Fig. 1, step 3) releases an energy of $-8.03 \mathrm{eV}$. As in the case of the first Ce atom, the incoming second $\mathrm{Ce}$ atom releases three electrons, one of them does not go to the relatively high energy $\mathrm{Ti} 3 d$ levels, but rather to the lower energy $\mathrm{Ce} 4 f$ of the $\mathrm{CeO}_{2}$ monomer. Therefore, the $\mathrm{Ce}^{4+}$ of the monomer is reduced to $\mathrm{Ce}^{3+}$. If we now move this second $\mathrm{Ce}$ atom close to the neighbors of the first $\mathrm{Ce}$ atom, there is a release of energy that becomes larger when it is placed in between the two extra $\mathrm{O}$ atoms from the $\mathrm{CeO}_{2}$ monomer and a row of bridge $\mathrm{O}$ of the $\mathrm{TiO}_{2}(110)$ surface (Fig. 1, step 4), the stabilization being in this case of $-2.45 \mathrm{eV}$. Formally it corresponds to a $\mathrm{Ce}_{2} \mathrm{O}_{2}$ dimer adsorbed on the surface. The energy exchange for the whole process, i.e. direct transformation from steps 2 to 4 , would be 
as large as $-10.48 \mathrm{eV}$. This highly exothermic process clearly implies that as long as "free" Ce atoms and monomers coexist on the surface, dimers will be formed from their interaction. The oxidation state for both $\mathrm{Ce}$ atoms in the dimer was $\mathrm{Ce}^{3+}$. The process could be described as

$$
\begin{aligned}
& \mathrm{CeO}_{2}\left(\mathrm{Ce}^{4+}\right) \text { on } \mathrm{TiO}_{2}+\mathrm{Ce}+2 \mathrm{Ti}^{4+}\left(\mathrm{TiO}_{2}\right) \\
& \rightarrow \mathrm{Ce}_{2} \mathrm{O}_{2}\left(\mathrm{Ce}^{3+}\right) \text { on } \mathrm{TiO}_{2}+2 \mathrm{Ti}^{3+}\left(\mathrm{TiO}_{2}\right) .
\end{aligned}
$$

We will now consider the interaction of a $\mathrm{Ce}_{2} \mathrm{O}_{2}$ dimer with oxygen to form a dimer with a composition of $\mathrm{Ce}_{2} \mathrm{O}_{3}$ (Fig. 1, steps 4 and 5). It is well known that the presence of oxygen vacancies on $\mathrm{TiO}_{2}(110)$ (which formally involves two $\mathrm{Ti}^{3+}$ cations/vacancy) generates adsorbed $\mathrm{O}$ atoms under oxygen pressure. After deposition of $\mathrm{Ce}$ atoms and formation of the first dimers we have generated $\mathrm{Ti}^{3+}$ species [see Eqs. (1) and (3)] which are able to dissociate oxygen. The presence of such adsorbed $\mathrm{O}$ atoms after $\mathrm{Ce}$ deposition under oxygen pressure were observed in STM images, ${ }^{21}$ and prompted us to consider models with a extra atomic oxygen adsorbed on the surface. Indeed, the $\mathrm{O}$ atoms readily react with the surface reoxidizing $\mathrm{Ti}^{3+}$ centers and forming $\mathrm{Ce}_{2} \mathrm{O}_{3}$ dimer. The process could be described as

$$
\begin{aligned}
& \mathrm{Ce}_{2} \mathrm{O}_{2}\left(\mathrm{Ce}^{3+}\right) \text { on } \mathrm{TiO}_{2}+2 \mathrm{Ti}^{3+}\left(\mathrm{TiO}_{2}\right)+\frac{1}{2} \mathrm{O}_{2} \\
& \rightarrow \mathrm{Ce}_{2} \mathrm{O}_{3}\left(\mathrm{Ce}^{3+}\right) \text { on } \mathrm{TiO}_{2} .
\end{aligned}
$$

The energy that is released in this process is $-2.59 \mathrm{eV}$ and the structure obtained is reported in Fig. 1, step 5.

Let us now complete the oxidation of the system by adding an extra oxygen atom, i.e., the transformation from the $\mathrm{Ce}_{2} \mathrm{O}_{3}$ dimer to two $\mathrm{CeO}_{2}$ monomers (Fig. 1, steps 5 and $6)$. As can be seen the process is exothermic but, in contrast to the previous oxidation step, (steps $4 \rightarrow 5$ ), the released energy amounts for only $-0.92 \mathrm{eV}$ (roughly one third). The reason for this is that now there are no longer high energy $\mathrm{Ti}$ $3 d$ electrons but two electrons in relatively low energy Ce $4 f$ states. Since the incoming O $2 p$ states are lower in energy than the $4 f$, the electronic transfer process from $4 f$ to $2 p$ states is still favorable, but the released energy is much lower. This means that as long as $\mathrm{Ti}^{3+}$ species exist, $\mathrm{O}_{2}$ will prefer to adsorb and dissociate on them because the stabilization energy for the system is much higher. Therefore, even though the oxidation process of dimers is favorable, it is not the preferred site for the adsorption and dissociation of $\mathrm{O}_{2}$. In consequence, the oxidation of $\mathrm{Ce}_{2} \mathrm{O}_{3}$ will not happen until all the $\mathrm{Ti}^{3+}$ species completely disappear from the system. The process could be described as

$$
\mathrm{Ce}_{2} \mathrm{O}_{3}\left(\mathrm{Ce}^{3+}\right) \text { on } \mathrm{TiO}_{2}+\frac{1}{2} \mathrm{O}_{2} \rightarrow 2 \mathrm{CeO}_{2}\left(\mathrm{Ce}^{4+}\right) \text { on } \mathrm{TiO}_{2} \text {. }
$$

\section{B. Formation energy and redox properties}

The structures seen in Fig. 1 and in STM images ${ }^{21}$ for the ceria clusters in contact with $\mathrm{TiO}_{2}(110)$ are quite different from the fluorite structure characteristic of bulk $\mathrm{CeO}_{2}$. Furthermore, the energetic analysis that we have discussed so far might appear surprising if we compare it with the same process in bulk. The energy involved in the oxidation process
TABLE I. Formation energies (eV) per Ce atom (see the text for details) of bulk and adsorbed-particle phases of $\mathrm{CeO}_{2}$ and $\mathrm{Ce}_{2} \mathrm{O}_{3}$ species. The differences between the phases for each species and between the species for each phase are shown for easy measuring of the supported-particle effect on the formation energy $(0.87 \mathrm{eV} / \mathrm{Ce}$ atom).

\begin{tabular}{lrcc}
\hline \hline & Bulk & Particle on surface & $\Delta E$ (particle-bulk) \\
\hline $\mathrm{CeO}_{2}$ & -14.50 & -13.88 & 0.62 \\
$\mathrm{Ce}_{2} \mathrm{O}_{3}$ & -13.22 & -13.47 & -0.25 \\
$\Delta E\left(\mathrm{Ce}_{2} \mathrm{O}_{3}-\mathrm{CeO}_{2}\right)$ & 1.28 & 0.41 & 0.87 \\
\hline \hline
\end{tabular}

from $\mathrm{Ce}_{2} \mathrm{O}_{3}$ (bulk) to $2 \mathrm{CeO}_{2}$ (bulk) in the presence of $\frac{1}{2} \mathrm{O}_{2}$ $(g)$ is $-2.56 \mathrm{eV}$ (theory) and $-3.95 \mathrm{eV}$ (exp), respectively. ${ }^{57}$ The fact that the oxidation is less favored when $\mathrm{CeO}_{x} \mathrm{NPs}$ are supported on the $\mathrm{TiO}_{2}(110)$ surface might arise from two possibilities: either $\mathrm{Ce}_{2} \mathrm{O}_{3} \mathrm{NPs}$ are stabilized, or $\mathrm{CeO}_{2} \mathrm{NPs}$ are destabilized when they are deposited on the titania surface, and of course it may also due to a combination of both contributions. In order to try to quantify these effects we have estimated the formation energy for such mixed-metal oxide phases, and compared with the formation of the bulk phases. The formation energy (per $\mathrm{Ce}$ atom) for the bulk phase may be written as

$$
\Delta E_{f}\left(\mathrm{CeO}_{x}\right)=E\left(\mathrm{CeO}_{x}\right)-E(\mathrm{Ce}, \text { atom })-\frac{x}{2} E\left(\mathrm{O}_{2}, g\right)
$$

and for the particles on the surface as

$$
\begin{aligned}
\Delta E_{f}\left(\mathrm{CeO}_{x}\right)= & E\left(\mathrm{CeO}_{x} / \mathrm{TiO}_{2}\right)-E\left(\mathrm{TiO}_{2}, \mathrm{slab}\right) \\
& -E(\mathrm{Ce}, \text { atom })-\frac{x}{2} E\left(\mathrm{O}_{2}, g\right),
\end{aligned}
$$

where $E\left(\mathrm{CeO}_{x}\right)$ is the bulk energy per $\mathrm{Ce}$ atom, $E\left(\mathrm{CeO}_{x} / \mathrm{TiO}_{2}\right)$ is the energy of the $\mathrm{TiO}_{2}$ slab with a $\mathrm{CeO}_{x}$ particle adsorbed, $E(\mathrm{Ce}$, atom) is the energy of one $\mathrm{Ce}$ atom, $E\left(\mathrm{O}_{2}, g\right)$ is the energy of the $\mathrm{O}_{2}$ molecule, and $E\left(\mathrm{TiO}_{2}\right.$, slab) is the energy of the $\mathrm{TiO}_{2}$ slab. It is known that the formation energy is calculated with respect to the most stable phase (in this case we should use for Ce the energy from metallic bulk $\mathrm{Ce}$ per $\mathrm{Ce}$ atom). However, we are not interested in the exact values for the formation energy but in the difference among them, which is the same and not dependent on the reference energy for Ce. The results are shown in Table I.

The formation energy for a $\mathrm{CeO}_{2}$ particle on the surface is lower (in absolute value) than for bulk $\mathrm{CeO}_{2}$. It means that the particle would prefer to be as $\mathrm{CeO}_{2}$ bulk rather than an isolated particle on $\mathrm{TiO}_{2}(110)$. This is rather easy to understand, considering the reduction on coordination with the $\mathrm{O}$ atoms and the loss of Madelung energy. The instability introduced by the change in environment is $0.62 \mathrm{eV} / \mathrm{Ce}$ atom (see Table I). Instead, the $\mathrm{Ce}_{2} \mathrm{O}_{3}$ particle is stabilized on the surface with respect to the bulk by $-0.25 \mathrm{eV} / \mathrm{Ce}$ atom (see Table I). Therefore, the combined effect of the $\mathrm{Ce}_{2} \mathrm{O}_{3}$ stabilization and the $\mathrm{CeO}_{2}$ destabilization on the surface is the responsible for reducing the relative stability of $\mathrm{CeO}_{2}$ and $\mathrm{Ce}_{2} \mathrm{O}_{3}$ from $1.28 \mathrm{eV} / \mathrm{Ce}$ atom in the bulk to $0.41 \mathrm{eV} / \mathrm{Ce}$ atom when in the form of a mixed-metal oxide on $\mathrm{TiO}_{2}(110)$. Our calculations show that the destabilization of $\mathrm{CeO}_{2}$ is significantly higher than the stabilization of $\mathrm{Ce}_{2} \mathrm{O}_{3}$ (see Table I). 
TABLE II. Redox properties of the couple $\mathrm{Ce}_{2} \mathrm{O}_{3} / \mathrm{CeO}_{2}$ measured through their reaction energies with $\mathrm{CO} / \mathrm{O}_{2}$ for supported particle and bulk phases. The difference in the reaction energy between both phases for each reaction is shown for easy measuring of the supported-particle effect.

\begin{tabular}{lccrr}
\hline \hline & & Particles (P) & Bulk (B) & $\Delta(\mathrm{P}-\mathrm{B})$ \\
\hline Oxidation & $\mathrm{Ce}_{2} \mathrm{O}_{3}+\frac{1}{2} \mathrm{O}_{2} \rightarrow 2 \mathrm{CeO}_{2}$ & -0.92 & -2.56 & 1.64 \\
Reduction & $2 \mathrm{CeO}_{2}+\mathrm{CO} \rightarrow \mathrm{Ce}_{2} \mathrm{O}_{3}+\mathrm{CO}_{2}$ & -2.35 & -0.71 & -1.64 \\
\hline \hline
\end{tabular}

The fact that the formation energies of $\mathrm{CeO}_{2}$ and $\mathrm{Ce}_{2} \mathrm{O}_{3}$ are similar in the case of a mixed-metal oxide (the difference is only $0.41 \mathrm{eV}$ in $13.88 \mathrm{eV}$, i.e. $3 \%$ ) means that the system is almost equally stabilized, on a per $\mathrm{Ce}$ atom basis, by the formation of $\mathrm{CeO}_{2}$ monomers or $\mathrm{Ce}_{2} \mathrm{O}_{3}$ dimers. This result appears to be of great importance for catalysis on cerium oxides, as the $\mathrm{CeO}_{2} \leftrightarrow \mathrm{Ce}_{2} \mathrm{O}_{3}$ conversion has been found to play an essential role in many catalytic processes as the three-way car exhaust catalysis, $\mathrm{SO}_{x}$ destruction, alcohol synthesis from hydrogenation of $\mathrm{CO}$ or $\mathrm{CO}_{2}$, and the water gas shift reaction. ${ }^{58-60}$ There is evidence that in these cases $\mathrm{CeO}_{2}$ does not only work as a support for different precious metals, but rather, due to its facile reducibility, ceria can also directly participate in different steps of the catalytic process. Its activity is precisely ascribed to its oxygen storage capacity, ${ }^{58,60}$ i.e., easily taking up and releasing oxygen under oxidizing and reducing conditions, respectively, which takes place according to the formal reaction scheme: $2 \mathrm{CeO}_{2} \rightarrow \mathrm{Ce}_{2} \mathrm{O}_{3}+0.5 \mathrm{O}_{2}$. Our calculations bring theoretical evidence that the energetic preference for this reaction can be related to the similarity of the formation energy of $\mathrm{Ce}^{3+}$ and $\mathrm{Ce}^{4+}$ species on the $\mathrm{TiO}_{2}(110)$ substrate. It also suggests that we could easily tune the system to favor a given oxidation state, as the main final oxidation state will be determined by the specific conditions under which the reaction takes place, but not by the intrinsic nature of the Ce species. If the system reacts with reducing species the main final oxidation states will be $\mathrm{Ce}^{3+}$ while an oxidizing environment will lead the system to $\mathrm{Ce}^{4+}$. So, if the oxygen storage capacity is high in the bulk phase, it will be even higher in the mixed-metal oxide phase at the nanometer level in the system $\mathrm{CeO}_{x} / \mathrm{TiO}_{2}$, what allows us to expect a higher catalytic activity than that of bare $\mathrm{CeO}_{2}$. This has been shown for the WGS reaction case where the catalytic activity of $M / \mathrm{CeO}_{x} / \mathrm{TiO}_{2}(M=\mathrm{Au}$, $\mathrm{Cu}$ or $\mathrm{Pt}$ ) was found to be more than two times higher than that of $M / \mathrm{CeO}_{2}$ or $M / \mathrm{TiO}_{2}{ }^{21,32}$

To check the effect of environment on the $\mathrm{CeO}_{2} \leftrightarrow \mathrm{Ce}_{2} \mathrm{O}_{3}$ exchange, we have calculated the energies involved in the processes of oxidation of $\mathrm{Ce}_{2} \mathrm{O}_{3}$ with $\mathrm{O}_{2}$ to give $\mathrm{CeO}_{2}$, and reduction in $\mathrm{CeO}_{2}$ with $\mathrm{CO}$ to give $\mathrm{CO}_{2}$ and $\mathrm{Ce}_{2} \mathrm{O}_{3}$. Table II shows the energetics for both bulk ceria and $\mathrm{CeO}_{x}$ NPs supported on $\mathrm{TiO}_{2}(110)$. In the bulk phase, it has been experimentally found that the oxidation process is strongly favored $(-3.95 \mathrm{eV})$ while the reduction process by $\mathrm{CO}$ is not (the energy cost is $1.02 \mathrm{eV}) .{ }^{57}$ Our DFT calculations show a similar trend: the oxidation is more favored than the reduction $(-2.56 \mathrm{eV}$ versus $-0.71 \mathrm{eV})$. We can see in Table II that the tendency in the mixed-metal oxide phase at the nanometer level is just the opposite than in bulk phase.
The reduction by $\mathrm{CO}$ is now clearly more favored $(-2.35$ $\mathrm{eV})$ than the oxidation $(-0.92 \mathrm{eV})$. Therefore, an inversion of the oxidation-reduction tendency of the system takes place when we move from bulk to $\mathrm{CeO}_{x}$ particles supported on $\mathrm{TiO}_{2}$. At the nanometer level the mixed-metal oxide effect on the redox properties of the couple $\mathrm{Ce}_{2} \mathrm{O}_{3} / 2 \mathrm{CeO}_{2}$ could be estimated to be $1.64 \mathrm{eV}$, as the reduction process is favored by $-1.64 \mathrm{eV}$ and the oxidation hampered by $1.64 \mathrm{eV}$ with respect to the bulk (see Table II). Our conclusion that to reduce $\mathrm{Ce}^{4+}$ to $\mathrm{Ce}^{3+}$ is easier for the mixed-metal oxide, was confirmed by comparing the behavior of $\mathrm{CeO}_{2}(111)$ and $\mathrm{CeO}_{x} / \mathrm{TiO}_{2}(110)$. For example, a $\mathrm{CeO}_{2}(111)$ surface did not undergo reduction under an atmosphere of 20 Torr of $\mathrm{CO}$ at $400 \mathrm{~K}$, while a $\mathrm{CeO}_{2} / \mathrm{TiO}_{2}(110)$ surface under the same conditions was completely transformed into $\mathrm{Ce}_{2} \mathrm{O}_{3} / \mathrm{TiO}_{2}(110){ }^{21}$

\section{C. $\mathrm{TiO}_{x}$ versus $\mathrm{CeO}_{x}$ particles on $\mathrm{TiO}_{2}(110)$}

In a recent article the formation of $\mathrm{TiO}_{x}$ clusters on the $\mathrm{TiO}_{2}$ surface, formed by direct interaction of $\mathrm{O}_{2}$ with interstitials Ti atoms which move from the bulk to the surface, has been reported. ${ }^{33}$ To compare the behavior of $\mathrm{CeO}_{x}$ and $\mathrm{TiO}_{x}$ species on $\mathrm{TiO}_{2}$ we report in Fig. 1 the adsorptionoxidation path for Ti. As can be seen the $M^{4+}$ states (where $M$ is the metal) are more stable for Ti than for Ce (Fig. 1, steps 2 and 6). In contrast, the $M^{3+}$ states are always more stable with Ce than with Ti (Fig. 1, steps 1, 3-5). The difference is due to the higher energy of the $3 d \mathrm{Ti}^{3+}$ valence electron (see Fig. 2), while for $\mathrm{Ce}^{3+}$ the $4 f$ electron is in a significantly lower level. In this case, the Ce center is neither greatly destabilized by forming $\mathrm{Ce}^{3+}$ nor greatly stabilized when moves to $\mathrm{Ce}^{4+}$. This is in contrast to $\mathrm{Ti}$, which is relatively more destabilized when reduced to $\mathrm{Ti}^{3+}$ and, consequently, the stabilization is much higher when it is reoxidized to $\mathrm{Ti}^{4+}$. This makes the oxidation step from supported $\mathrm{Ti}_{2} \mathrm{O}_{3}$ to $\mathrm{TiO}_{2}$ in $\mathrm{O}_{2}$ presence much more favored $-3.23 \mathrm{eV}$ than the same step in the case of $\mathrm{Ce}(-0.92 \mathrm{eV})$ (see Fig. 1, steps $5 \rightarrow 6$ ). It also explains that the reduction from supported $\mathrm{TiO}_{2}$ to $\mathrm{Ti}_{2} \mathrm{O}_{3}$ in the presence of $\mathrm{CO}$ is almost thermoneutral $(-0.04 \mathrm{eV})$, while the same step in the case of supported ceria is neatly exothermic $-2.35 \mathrm{eV}$.

\section{Electronic structure and the relative stability}

Overall, our calculations show that $\mathrm{Ce}_{2} \mathrm{O}_{3}$ is stabilized as mixed-metal oxide on the surface of $\mathrm{TiO}_{2}$ compared to the bulk phase, while $\mathrm{CeO}_{2}$ is destabilized. As a result, the $\mathrm{TiO}_{2}$-supported ceria cluster can be oxidized or reduced in a much easier way than the bulk materials. To better understand the different stability between these phases, we have calculated the DOS projected on $\mathrm{Ce}$ and $\mathrm{O}$ atoms in both bulk and supported-particle phases for $\mathrm{Ce}_{2} \mathrm{O}_{3}$ and $\mathrm{CeO}_{2}$. Here, the DOS for the isolated free particle with the same geometry that the supported particle has also been included for comparison, in order to determine the effect of the structure of the NP and the effect of the interaction with the support. As shown in Fig. 3, the formation of the mixed-metal oxide involves significant changes in the electronic structure. For the free particle, molecular bands with strongly mixed Ce $4 f$ and O $2 p$ were observed, indicating a high degree of 


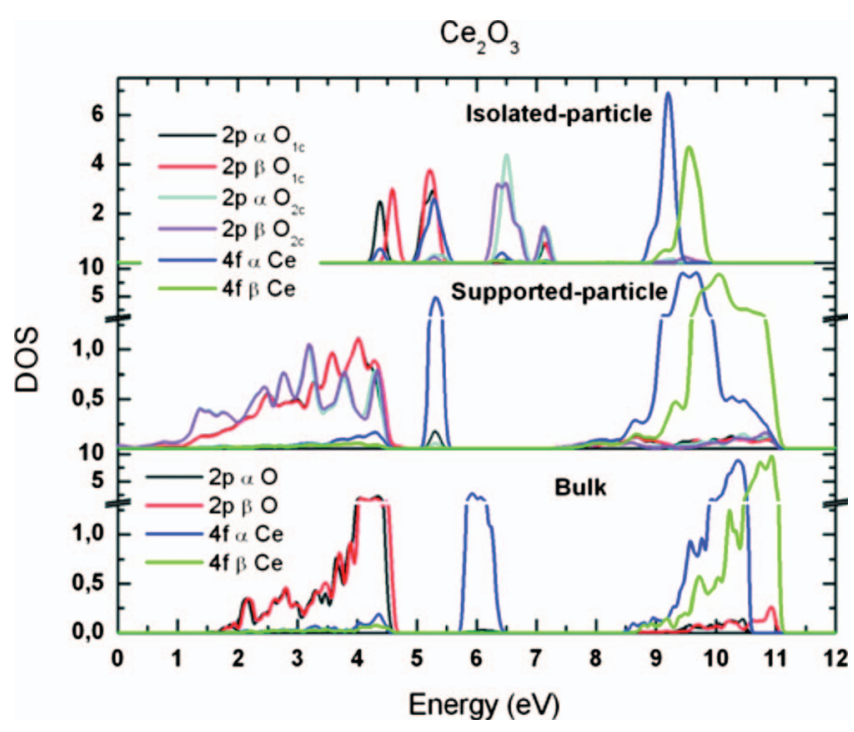

FIG. 3. DOS projected on $\mathrm{Ce}$ and $\mathrm{O}$ atoms of the $\mathrm{Ce}_{2} \mathrm{O}_{3}$ unit for the systems: perfect bulk (bottom), supported particle on $\mathrm{TiO}_{2}(110)$ (middle), and isolated particle with the same geometry than that of the supported one (top). $\mathrm{O}_{1 \mathrm{c}}$ and $\mathrm{O}_{2 \mathrm{c}}$ stand for oxygen atoms mono- and bi-coordinated to $\mathrm{Ce}$ atoms respectively.

covalency. That is, the isolated $\mathrm{Ce}_{2} \mathrm{O}_{3}$ unit is electronically transformed into a molecule. However, when this particle is deposited on $\mathrm{TiO}_{2}$, the electronic structure of the particle returns to a solidlike DOS with wide $\mathrm{O} 2 p$ and Ce $4 f$ bands (see Fig. 3).The effect of the interaction with the support is very important since it "crystallizes" the electronic structure of the cerium oxide particle from an initial "molecular" distribution, leading to a true mixed-metal oxide rather than a supported particle.

Compared to bulk $\mathrm{Ce}_{2} \mathrm{O}_{3}$, the $2 p$ and $4 f$ main bands are wider in the nanomixed-metal oxide. As a consequence, after deposition, the band-gap between the top of the $\mathrm{O} 2 p$ band and the bottom of the main Ce $4 f$ band is reduced by 1.44 $\mathrm{eV}$. In addition, the Ce $4 f$ band, that corresponds to the valence electron of the reduced specie $\mathrm{Ce}^{3+}$ and locates in the midband gap between the main $\mathrm{O} 2 p$ and the conduction bands, is shifted by $0.8 \mathrm{eV}$ to the lower energies in the mixed-metal oxide. In other words, the $4 f$ valence electron of $\mathrm{Ce}^{3+}$ is stabilized with respect to bulk phase. As shown in Fig. 3, there is almost no gap between the $\mathrm{O} 2 p$ band and $4 f$ $\mathrm{Ce}^{3+}$ little band in the mixed-metal oxide. This close distribution allows a higher mixing between the two bands, and therefore increases the covalent character of the bond. In fact, we can see in Fig. 3 that $\mathrm{O} 2 p$ band appears at the same energy as $\mathrm{Ce}^{3+} 4 f$ band, indicating a certain covalent character of the $\mathrm{Ce}-\mathrm{O}$ bond in the particle. In contrast, the $\mathrm{Ce}-\mathrm{O}$ overlapping is, however, much lower in the bulk phase. Furthermore, the width of the little $4 f$ peak of $\mathrm{Ce}^{3+}$ is also reduced by $0.25 \mathrm{eV}$ when going from bulk to surface nanomixed-metal oxide, indicating a more localized molecular feature (approaching a single level energy like in the molecules) with respect to the bulk. That is, the $\mathrm{Ce}_{2} \mathrm{O}_{3}$ unit seems to be crystallized by the interaction with the support, but some covalent character coming from the molecular electronic structure of the isolated particle remains in the sup-

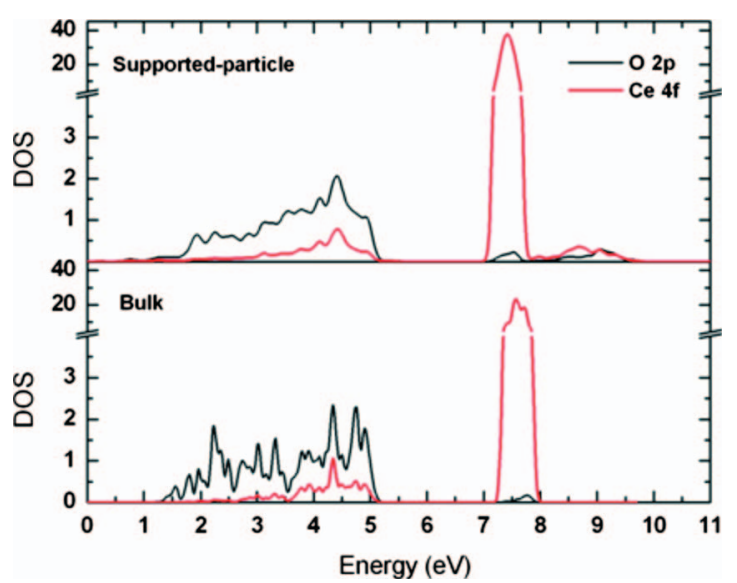

FIG. 4. DOS projected on $\mathrm{Ce}$ and $\mathrm{O}$ atoms of the $\mathrm{CeO}_{2}$ unit for the systems: perfect bulk (bottom) and supported particle on $\mathrm{TiO}_{2}(110)$ (top).

ported particle. This remaining covalency helps stabilizing the supported $\mathrm{Ce}_{2} \mathrm{O}_{3}$ unit by lowering the energy of the $\mathrm{Ce}^{3+}$ $4 f$ band.

As the $4 f$ band of fully oxidized $\mathrm{Ce}^{4+}$ is completely empty no electronic-induced change in the energy is expected by the interaction with the support. Indeed, no significant differences are observed when the DOS of the supported $\mathrm{CeO}_{2}$ unit and that of the bulk are compared (Fig. 4). Therefore, there is no electronic stabilization in the $\mathrm{CeO}_{2}$ unit when going from bulk to surface nanomixed-metal oxide. Accordingly, the loss of the Madelung potential and coordination with $\mathrm{O}$ atoms is not electronically compensated, and $\mathrm{CeO}_{2}$ is more stable as bulk phase than as nanomixed-metal oxide on the $\mathrm{TiO}_{2}$ surface.

\section{E. Adsorption and dissociation of $\mathrm{H}_{2} \mathrm{O}$ on $\mathrm{CeO}_{x} / \mathrm{TiO}_{2}(110)$}

As stated in Sec. I, all the steps involved in the WGS reaction can take place on the surfaces of the plain metals or metal NPs, but for the dissociation of $\mathrm{H}_{2} \mathrm{O}$ a high activation barrier has been predicted. ${ }^{24,25}$ In contrast, water easily dissociates on the metal oxide, therefore, an adequate coupling of the oxide and metal properties leads to a high active catalyst. That is why $\mathrm{Au} / \mathrm{TiO}_{2}$ or $\mathrm{Cu} / \mathrm{TiO}_{2}$ are efficient WGS catalysts. ${ }^{22}$ The activation energy for the dissociation of $\mathrm{H}_{2} \mathrm{O}$ on $\mathrm{TiO}_{2}$ oxygen vacancies has been calculated to be $0.35 \mathrm{eV}$ (Ref. 27) while on the (111) surface of $\mathrm{Au}$ and $\mathrm{Cu}$ the barrier increases to $1.95 \mathrm{eV}$ (Ref. 61) and $1.36 \mathrm{eV}^{62}$ respectively. Although, the presence of steps in the metal surfaces can decrease the activation energy for the dissociation of $\mathrm{H}_{2} \mathrm{O}$ on $\mathrm{Cu}$ from $1.36 \mathrm{eV}$ in $\mathrm{Cu}(111)$ to $0.9 \mathrm{eV}$ (or $0.71 \mathrm{eV}$ with the zero-point correction) in $\mathrm{Cu}(321),{ }^{63}$ the activation energy is still twice the activation barrier in the $\mathrm{TiO}_{2}(110)$ oxygen vacancy. Therefore, any oxide, which decreases the barrier for the dissociation of $\mathrm{H}_{2} \mathrm{O}$, is expected to improve the catalytic activity of the system $M / M \mathrm{O}_{x}$ (where $M$ is a metal). Since we have shown that the $\mathrm{Au} / \mathrm{CeO}_{x} / \mathrm{TiO}_{2}$ system is three times more active than $\mathrm{Au} / \mathrm{TiO}_{2}$ for the WGS reaction and four times more active than $\mathrm{Cu} / \mathrm{ZnO}$, the most common WGS catalyst used in the industry, ${ }^{21}$ it has been postulated that the barrier for the water dissociation on the $\mathrm{CeO}_{x}$ par- 


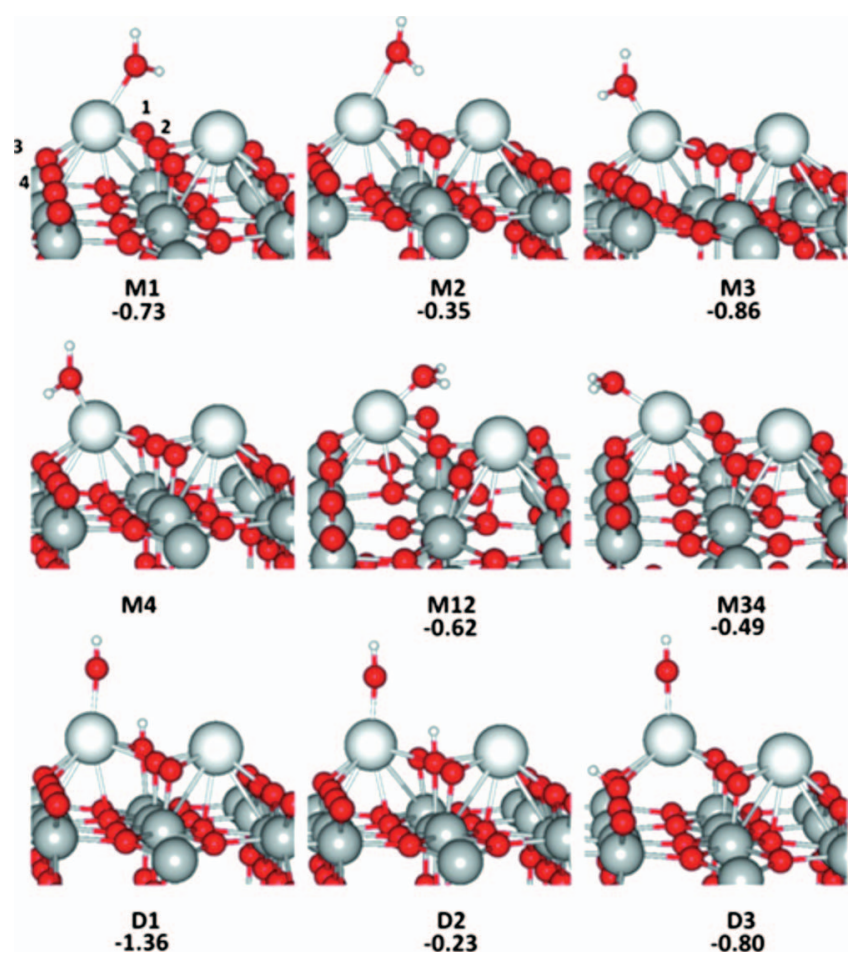

FIG. 5. Adsorption sites, geometries, and adsorption energies $(\mathrm{eV})$ for the dissociation of water on $\mathrm{Ce}_{2} \mathrm{O}_{3} / \mathrm{TiO}_{2}(110)$. In order to simplify the view only the $\mathrm{Ce}_{2} \mathrm{O}_{3}$ particle and water are shown in the figure. The nonequivalent oxygen atoms have been labeled as: 1, 2, 3, and 4. Atom colors: red (O), dark gray (Ti), white (big spheres, Ce) and white (small spheres, H).

ticles will be smaller than on $\mathrm{TiO}_{2-x}$. With the aim to confirm this aspect we report here an energetic analysis for the dissociation of water on $\mathrm{CeO}_{x} / \mathrm{TiO}_{2}(110)$.

To begin our analysis we examined the adsorption of a water molecule in the molecular and dissociated forms. Two different orientations were taken into account in which water can establish one or two hydrogen bonds (Fig. 5). Labels M and $\mathrm{D}$ refer to molecularly and dissociatively adsorbed water molecules, while the numbers indicate the oxygen atom to which is bound through hydrogen bond. Results for adsorption energies are reported in Fig. 5. For the molecular case, the larger interaction energy is $-0.86 \mathrm{eV}$ ( site M3), although there is another site, (M1) slightly less favored $(-0.73 \mathrm{eV})$. However, in the case of dissociated water there is a clear preference for site D1, where the transferred hydrogen binds oxygen $\mathrm{O} 1$ (see Fig. 5) that is the one with lower coordination, and therefore, the one with larger basicity. Given that the D1 site is by far the most stable, we considered a path for the water dissociation process, that may be easily visualized as the cleavage of an $\mathrm{O}-\mathrm{H}$ bond starting from the configuration corresponding to M1 (Fig. 6). The transition state search using the CI-NEB algorithm showed an activation barrier of only $0.04 \mathrm{eV}$, i.e., eight times smaller than that found in the $\mathrm{TiO}_{2}$ oxygen vacancy (see Fig. 6). ${ }^{27}$ Moreover, the reaction energy for the dissociation of water on $\mathrm{CeO}_{x} / \mathrm{TiO}_{2}$ was found to be $-0.70 \mathrm{eV}$, while on the oxygen vacancies of $\mathrm{TiO}_{2}$ the estimated value was $\sim-0.4 \mathrm{eV}$. These results unambiguously indicate the larger ability of $\mathrm{CeO}_{x} / \mathrm{TiO}_{2}$ to dissociate water and, therefore, can help to explain the superior WGS catalytic activity of the $M / \mathrm{CeO}_{x} / \mathrm{TiO}_{2} \quad(M$ $=\mathrm{Au}, \mathrm{Cu}, \mathrm{Pt}$ ) systems over $M / \mathrm{TiO}_{2} \cdot{ }^{21,32}$

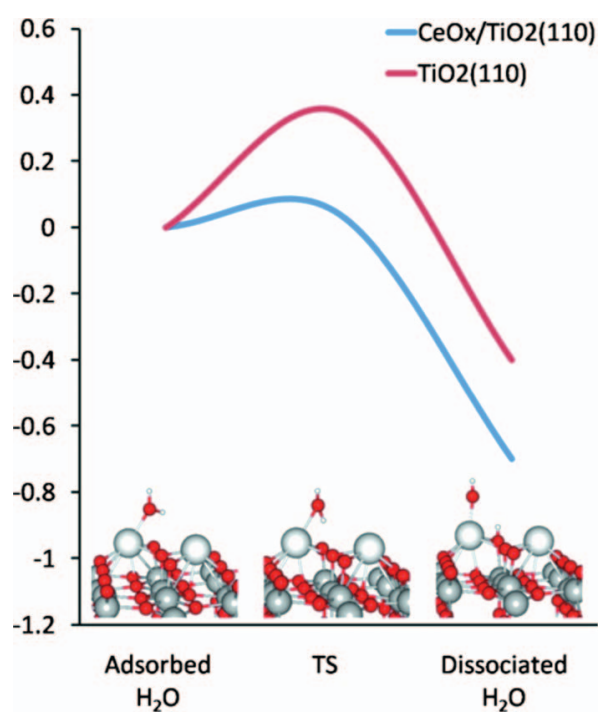

FIG. 6. Energy pathway for the dissociation of a $\mathrm{H}_{2} \mathrm{O}$ molecule on $\mathrm{Ce}_{2} \mathrm{O}_{3} / \mathrm{TiO}_{2}(110)$ (our calculations) and on an oxygen vacancy of $\mathrm{TiO}_{2}(110)$ (Ref. 27). Initial and final geometries for the dissociation on $\mathrm{Ce}_{2} \mathrm{O}_{3} / \mathrm{TiO}_{2}(110)$ are shown. While for reduced $\mathrm{TiO}_{2}(110)$ surface the reaction energy is $\sim-0.4 \mathrm{eV}$ with an activation barrier of $0.35 \mathrm{eV}$, for $\mathrm{Ce}_{2} \mathrm{O}_{3} / \mathrm{TiO}_{2}(110)$ the reaction energy is more exothermic $(-0.7 \mathrm{eV})$ with an activation barrier of only $0.04 \mathrm{eV}$. For atom colors see Fig. 5 .

\section{SUMMARY AND CONCLUSIONS}

In this paper we report a theoretical study of the structural and electronic properties of $\mathrm{CeO}_{x}$ species supported on the rutile $\mathrm{TiO}_{2}$ (110) surface by means of periodic GGA density-functional calculations that include a Hubbard-like correction $U_{\text {eff. }}$ Deposition of Ce followed by reaction with $\mathrm{O}_{2}$ gives rise to the formation of $\mathrm{Ce}_{2} \mathrm{O}_{3}$ dimers diagonally arranged on the $\mathrm{TiO}_{2}(110)$ surface, in agreement with the experimental observations. The redox properties of these $\mathrm{CeO}_{x}$ NPs haven been analyzed and found to be quite different from those of bulk ceria. Thus, the reduction process: $2 \mathrm{CeO}_{2}+\mathrm{CO} \rightarrow \mathrm{Ce}_{2} \mathrm{O}_{3}+\mathrm{CO}_{2}$ is favored over the oxidation reaction: $\mathrm{Ce}_{2} \mathrm{O}_{3}+(1 / 2) \mathrm{O}_{2} \rightarrow 2 \mathrm{CeO}_{2}$. Moreover, while, as expected, the $\mathrm{CeO}_{2}$ species are less stable as supported NPs on $\mathrm{TiO}_{2}(110)$ than as bulk, the $\mathrm{Ce}_{2} \mathrm{O}_{3}$ species are stabilized when they are supported. These results suggest that the $\mathrm{CeO}_{x} / \mathrm{TiO}_{2}$ interface behaves like a mixed-metal oxide rather than a supported $\mathrm{NP}$ of $\mathrm{CeO}_{x}$, and that this mixedmetal oxide favors the +3 oxidation state over the +4 under WGS reaction conditions. This is in contrast to the behavior of the $\mathrm{TiO}_{x} / \mathrm{TiO}_{2}(110)$ system, for which our calculations show that the reduced state $\mathrm{Ti}^{3+}$ is not favored over the $\mathrm{Ti}^{4+}$. This difference is obviously due to the fact that the $3 d$ occupied states in $\mathrm{Ti}^{3+}$ are significantly higher in energy than the $4 f$ states of $\mathrm{Ce}^{3+}$, and as a result, under WGS reaction conditions, a full oxidation of $\mathrm{Ti}$ is expected, with loss of the potential activity of $\mathrm{Ti}^{3+}$ centers.

The effect of a mixed-metal oxide at the nanometer level on the WGS catalytic activity has been analyzed by studying the interaction of the $\mathrm{CeO}_{x} / \mathrm{TiO}_{2}(110)$ system with water. The dissociation process is quite exothermic, $-0.70 \mathrm{eV}$, while the activation energy for the dissociation is estimated to be as small as $0.04 \mathrm{eV}$. This is in contrast to a common support widely used in these reactions, namely $\mathrm{TiO}_{2}$, for 
which the barrier for the dissociation in an oxygen vacancy has been calculated to be $0.35 \mathrm{eV}^{27}$ This larger ability of $\mathrm{CeO}_{x} / \mathrm{TiO}_{2}$ to dissociate water may help to explain the superior WGS catalytic activity of the $M / \mathrm{CeO}_{x} / \mathrm{TiO}_{2}(M$ $=\mathrm{Au}, \mathrm{Cu}, \mathrm{Pt}$ ) systems over $M / \mathrm{TiO}_{2}{ }^{21,32}$

\section{ACKNOWLEDGMENTS}

This work was supported by the Spanish Ministerio de Ciencia e Innovación, MICINN, (Grant Nos. MAT200501872 and CSD2008-0023), and Junta de Andalucía (Grant No. FQM-132). The work done at the Brookhaven Nat. Lab was funded by the U.S. Department of Energy, Division of Chemical Sciences (Grant No. DE-AC02-98CH10886). We also thank the computational resources provided by the Barcelona Supercomputing Center-Centro Nacional de Supercomputación (Spain).

${ }^{1}$ N. Kruse, A. Frennet, and J. -M.Bastin, Top. Catal. 16/17, 1 (2001).

${ }^{2}$ D. E. Webster, Top. Catal. 16/17, 33 (2001).

${ }^{3}$ Recent Advances in Catalysis for Hydrogen Production and Fuel Processing for Fuel Cells, edited by C. Song (Springer Science + Business Media, Luxembourg), Top Catal. 49, 1-24 (.2008).

${ }^{4}$ Catalysis by Gold, edited by G. J. Hutchings and D. W. Goodman (Springer Science + Business Media, Luxembourg), 44, 1-343 (2007).

${ }^{5}$ Catalysis by Gold, edited by G. J. Hutchings and M. Haruta (Elsevier, Amsterdam), Appl. Catal. A: Gen. 291, 1-262 (2005).

${ }^{6}$ R. Burch, Phys. Chem. Chem. Phys. 8, 5483 (2006)

${ }^{7}$ O. Thinon, F. Diehl, P. Avenier, and Y. Schuurman, Catal. Today 137, 29 (2008).

${ }^{8}$ M. Haruta, N. Yamada, T. Kobayashi, and S. Ijima, J. Catal. 115, 301 (1989).

${ }^{9}$ M. Valden, X. Lai, and D. W. Goodman, Science 281, 1647 (1998)

${ }^{10}$ M. S. Chen and D. W. Goodman, Science 306, 252 (2004).

${ }^{11}$ Q. Fu, H. Saltsburg, and M. Flytzani-Stephanopoulos, Science 301, 935 (2003).

${ }^{12}$ J. A. Rodriguez, P. Liu, J. Hrbek, J. Evans, and M. Perez, Angew. Chem., Int. Ed. 46, 1329 (2007)

${ }^{13}$ J. Guzman, S. Carrettin, J. C. Fierro-Gonzalez, B. C. Gates, and A. Corma, Angew. Chem., Int. Ed. 44, 4778 (2005).

${ }^{14}$ W. Deng and M. Flytzani-Stephanopoulos, Angew. Chem., Int. Ed. 45, 2285 (2006)

${ }^{15}$ R. Si and M. Flytzani-Stephanopoulos, Angew. Chem., Int. Ed. 47, 2884 (2008).

${ }^{16}$ M. S. Chen and D. W. Goodman, Top. Catal. 44, 41 (2007).

${ }^{17}$ C. T. Campbell and C. H. F. Peden, Science 309, 713 (2005)

${ }^{18}$ F. Esch, S. Fabris, L. Zhou, T. Montini, C. Africh, P. Fornasiero, G. Comelli, and R. Rosei, Science 309, 752 (2005).

${ }^{19} \mathrm{~S}$. Torbrügge, M. Reichling, A. Ishiyama, S. Morita, and O. Custance, Phys. Rev. Lett. 99, 056101 (2007).

${ }^{20}$ J. A. Rodriguez, S. Ma, P. Liu, J. Hrbeck, J. Evans, and M. Perez, Science 318, 1757 (2007).

${ }^{21}$ J. B. Park, J. Graciani, J. Evans, D. Stacchiola, S. Ma, P. Liu, A. Nambu, J. F. Sanz, J. Hrbek, and J. A. Rodriguez, Proc. Natl. Acad. Sci. U.S.A. 106, 4975 (2009).

${ }^{22}$ J. A. Rodríguez, J. Evans, J. Graciani, J. B. Park, and J. F. Sanz, J. Phys. Chem. C 113, 7364 (2009).

${ }^{23}$ J. A. Rodriguez, J. Graciani, J. Evans, J. B. Park, F. Yang, D. Stacchiola, S. D. Senanayake, S. Ma, M. Pérez, P. Liu, J. F. Sanz, and J. Hrbek, Angew. Chem., Int. Ed. 48, 8047 (2009).

${ }^{24}$ A. A. Phatak, W. N. Delgass, F. H. Ribeiro, and W. F. Schneider, J. Phys. Chem. C 113, 7269 (2009).

${ }^{25}$ P. Liu and J. A. Rodriguez, J. Chem. Phys. 126, 164705 (2007).

${ }^{26}$ M. A. Henderson, Surf. Sci. Rep. 46, 1 (2002).

${ }^{27}$ J. Oviedo, R. Sanchez-de-Armas, M. A. San Miguel, and J. F. Sanz, J.
Phys. Chem. C 112, 17737 (2008).

${ }^{28}$ T. Wu, W. E. Kaden, and S. L. Anderson, J. Phys. Chem. C 112, 9006 (2008).

${ }^{29}$ G. Ketteler, S. Yamamoto, H. Bluhm, K. Andersson, D. E. Starr, D. F. Ogletree, H. Ogasawara, A. Nilsson, and M. Salmeron, J. Phys. Chem. C 111, 8278 (2007).

${ }^{30}$ S.-C. Li, Z. Zhang, D. Sheppard, B. D. Kay, J. M. White, Y. Du, I. Lyubinetsky, G. Henkelman, and Z. Dohnalek, J. Am. Chem. Soc. 130, 9080 (2008)

${ }^{31}$ S. Kajita, T. Minato, H. S. Kato, M. Kawai, and T. Nakayama, J. Chem. Phys. 127, 104709 (2007).

${ }^{32}$ J. B. Park, J. Graciani, J. Evans, D. Stacchiola, S. D. Senanayake, L. Barrio, P. Liu, J. F. Sanz, J. Hrbek, and J. A. Rodriguez, J. Am. Chem. Soc. 132, 356 (2010).

${ }^{33}$ S. Wendt, P. T. Sprunger, E. Lira, G. K. H. Madsen, Z. Li, J. Ø. Hansen, J. Matthiesen, A. Blekinge-Rasmussen, E. Lægsgaard, B. Hammer, and F. Besenbacher, Science 320, 1755 (2008).

${ }^{34}$ G. Kresse and J. Joubert, Phys. Rev. B 59, 1758 (1999).

${ }^{35}$ J. Perdew, J. Chevary, S. Vosko, K. Jackson, M. Pederson, D. Singh, and C. Fiolhais, Phys. Rev. B 46, 6671 (1992).

${ }^{36}$ G. Kresse and J. Hafner, Phys. Rev. B 47, 558 (1993).

${ }^{37}$ G. Kresse and J. Furthmüller, Comput. Mater. Sci. 6, 15 (1996); Phys. Rev. B 54, 11169 (1996).

${ }^{38}$ K. J. Hameeuw, G. Cantele, D. Ninno, F. Trani, and G. Iadonesi, J. Chem. Phys. 124, 024708 (2006).

${ }^{39}$ S. J. Thompson and S. P. Lewis, Phys. Rev. B 73, 073403 (2006).

${ }^{40}$ J. Graciani, A. Nambu, J. Evans, J. A. Rodriguez, and J. F. Sanz, J. Am. Chem. Soc. 130, 12056 (2008).

${ }^{41}$ J. Graciani, L. J. Álvarez, J. A. Rodriguez, and J. F. Sanz, J. Phys. Chem. C 112, 2624 (2008).

${ }^{42}$ S. L. Dudarev, G. A. Botton, S. Y. Savrasov, C. J. Humphreys, and A. P. Sutton, Phys. Rev. B 57, 1505 (1998).

${ }^{43}$ S. Fabris, S. de Gironcoli, S. Baroni, G. Vicario, and G. Balducci, Phys. Rev. B 72, 237102 (2005).

${ }^{44}$ M. Cococcioni and S. de Gironcoli, Phys. Rev. B 71, 035105 (2005).

${ }^{45}$ C. W. M. Castleton, J. Kullgren, and K. Hermansson, J. Chem. Phys. 127, 244704 (2007).

${ }^{46}$ D. A. Andersson, S. I. Simak, B. Johansson, I. A. Abrikosov, and N. V. Skorodumova, Phys. Rev. B 75, 035109 (2007).

${ }^{47}$ M. Nolan, S. Grigoleit, D. C. Sayle, S. C. Parker, and G. W. Watson, Surf. Sci. 576, 217 (2005).

${ }^{48}$ M. Nolan, S. C. Parker, and G. W. Watson, Surf. Sci. 595, 223 (2005).

${ }^{49}$ M. Nolan, S. C. Parker, and G. W. Watson, J. Phys. Chem. B 110, 2256 (2006).

${ }^{50}$ M. B. Watkins, A. S. Foster, and A. L. Shluger, J. Phys. Chem. C 111, 15337 (2007).

${ }^{51}$ Z. Yang, Z. Lu, and G. Luo, Phys. Rev. B 76, 075421 (2007).

52 J. L. F. Da Silva, Phys. Rev. B 76, 193108 (2007).

${ }^{53}$ J. L. F. Da Silva, M. V. Ganduglia-Pirovano, J. Sauer, V. Bayer, and G. Kresse, Phys. Rev. B 75, 045121 (2007).

${ }^{54}$ C. Loschen, J. Carrasco, K. M. Neyman, and F. Illas, Phys. Rev. B 75, 035115 (2007).

${ }^{55}$ C. Loschen, A. Migani, S. T. Bromley, F. Illas, and K. M. Neyman, Phys. Chem. Chem. Phys. 10, 5730 (2008).

${ }^{56}$ G. Henkelman, B. Uberuaga, and H. Jonsson, J. Chem. Phys. 113, 9901 (2000).

${ }^{57}$ D. R. Lide, CRC Handbook of Chemistry and Physics, 87th ed. (CRC, Cleveland, 2006).

${ }^{58}$ A. Trovarelli, Catal. Rev. - Sci. Eng. 38, 439 (1996).

${ }^{59}$ M. Shelef and R. W. McCabe, Catal. Today 62, 35 (2000).

${ }^{60}$ A. Trovarelli, Catalysis by Ceria and Related Materials, 1st ed. (World Scientific, Singapore, 2002).

${ }^{61}$ S. Kandoi, A. A. Gokhale, L. C. Grabow, J. A. Dumesic, and M. Mavrikakis, Catal. Lett. 93, 93 (2004).

${ }^{62}$ A. A. Gokhale, J. A. Dumesic, and M. Mavrikakis, J. Am. Chem. Soc. 130, 1402 (2008).

${ }^{63}$ J. L. C. Fajín, M. N. D. S. Cordeiro, F. Illas, and J. R. B. Gomes, J. Catal. 268, 131 (2009). 